\title{
«Revue de l'Aire», «Recherches sur l'épistolaire», «Les supercherie épistolaires», Études réunies et présentées par Geneviève Haroche-Bouzinac
}

\section{Philippe Andrès}

\section{OpenEdition}

Journals

Édition électronique

URL : https://journals.openedition.org/studifrancesi/40846

DOI : 10.4000/studifrancesi.40846

ISSN : 2421-5856

Éditeur

Rosenberg \& Sellier

Édition imprimée

Date de publication : 1 juillet 2004

Pagination : 204

ISSN : 0039-2944

\section{Référence électronique}

Philippe Andrès, « «Revue de l'Aire», «Recherches sur l'épistolaire», «Les supercherie épistolaires», Études réunies et présentées par Geneviève Haroche-Bouzinac », Studi Francesi [En ligne], 142 (XLVIII I I) | 2004, mis en ligne le 30 novembre 2015, consulté le 09 septembre 2021. URL : http://

journals.openedition.org/studifrancesi/40846 ; DOI : https://doi.org/10.4000/studifrancesi.40846

Ce document a été généré automatiquement le 9 septembre 2021.

\section{c) $(\$)$}

Studi Francesi è distribuita con Licenza Creative Commons Attribuzione - Non commerciale - Non opere derivate 4.0 Internazionale. 


\title{
«Revue de l'Aire», «Recherches sur
} l'épistolaire», «Les supercherie épistolaires», Études réunies et présentées par Geneviève HarocheBouzinac

\author{
Philippe Andrès
}

\section{RÉFÉRENCE}

AA.VV., «Revue de l'Aire», «Recherches sur l'épistolaire», «Les supercherie épistolaires», Études réunies et présentées par GENEVIÈVE HAROCHE-BOUZINAC, $\mathrm{n}^{\circ} 28$, hiver 2002, pp. 205.

1 Dans ce numéro consacré à la fabrication de faux dans le domaine épistolaire, Geneviève HAROCHE-BOUZINAC pose, dès l'avant-propos, la problématique des «vraies fausses lettres, lettres fictives, à distinguer des lettres de fiction». Jean-Benoît PUECH, dans sa présentation, lance les grandes lignes d'une théorie où la fiction se développe «à l'intérieur du discours référentiel ou diction» (p. 13). Ainsi faut-il faire la différence entre «lettres fictieuses» et lettres réelles.

Parmi les articles, celui de Raffaelle MORABITO, «Histoire, fiction et vérité épistolaire» (pp. 51-57), constitue une brève synthèse sur la littérature italienne, concernant le lien entre fiction narrative ou dramatique et fait réel. Ainsi voit-on l'évolution de Manzoni qui finira par condamner l'invention au nom de la morale; chez Boccace, c'est la «position des personnes dans l'histoire» qui pose problème. Pour Le Tasse, dans la Jérusalem délivrée, la fiction devient «la recherche d'une vérité plus haute» (p. 53). Ainsi, jusque dans la correspondance privée, la frontière entre l'épistolaire et le romanesque se dilue, comme le prouve la correspondance étonnante, au début du XIX ${ }^{\mathrm{e}}$ siècle, entre 
Lorenzo Borsini et sa femme Gaetana, où le mensonge est le ressort secret de l'échange épistolaire.

3 Brigitte Louichon, dans son article sur «La lettre à Mérimée à propos d'Armance : du faux usage du vrai» (pp.85-92) s'interroge sur le secret de la lettre envoyée par Stendhal à Mérimée, le 23 décembre 1826: faut-il chercher la clef de l'énigme dans l'oeuvre de Claire de Duras (Ourika, 1824, et Edouard, 1825) et en conclure à l'impuissance d'Armance? Brigitte Louichon souligne cependant les incohérences de la réception critique de ce roman, mettant sur le même plan la lettre fictive d'Octave à Armance et celle de Stendhal à Mérimée. Ainsi, l'usage éditorial a-t-il contribué à populariser le «faux usage du vrai» et à créer une distorsion au niveau de la lecture.

4 Ces articles choisis parmi ceux du dossier thématique sont suivis de comptes rendus centrés sur l'édition actuelle de correspondances, et surtout d'une bibliographie que nous signalons pour sa richesse et son sérieux. 